\title{
S*-PROPER FUNCTIONS
}

\author{
Laheeb Muhsen No'man \\ Department of Mathematics, College of Science, Al-Mustansiryah University, Baghdad-Iraq.
}

\begin{abstract}
The main aim of this work is to study some types of proper functions, namely, $\mathrm{s}^{*}$-proper functions and we equivalent the definition of $s^{*}$-proper function by a new definition depending on filters. And we prove some propositions on this subject by using the last definition and we get some results about $\mathrm{s}^{*}$-proper functions.
\end{abstract}

\section{Introduction}

One of the most important concepts in mathematics and especially in topology is the concept of function. There are several types of functions, one of them is the important class of proper functions.

Many scientists, and researches studied the proper function such as Vainstein (1947), Leray (1950), Bourbaki (1951), Henrisken, Isbell (1958), Frolik (1960), Archange'skil (1967), Michel (1971), Chaber (1972), Pareck, Hedeib (1977), Jungck (1992) and Vermenlen (1994).

In this paper, we study a new type of proper functions, namely $\mathrm{s}^{*}$-proper function, the definition of $s^{*}$-proper function depend on $\mathrm{s}^{*}$-closed functions.

In this work, we equivalent the definition of $\mathrm{s}^{*}$-proper function by a new definition depending on filters, then the definition of $\mathrm{s}^{*}$ proper function become (a continuous function $\mathrm{f}$ from a topological space $\mathrm{X}$ into a topological space $\mathrm{Y}$ is called an $\mathrm{s}^{*}$-proper function if and only if $F$ is a filter on $X$ and if $y \in Y$ is a cluster point of $f(f)$, then there is an s-cluster point $x$ of $f$ such that $f(x)=y$.

We use the last definition to prove some propositions and we get some results as well as we give some examples on this subject.

We recall that a set $A$ of a topological space $X$ is said to be a semi-closed set (written s-closed) if and only if there exists a closed subset $F$ of $X$, such that $F^{o} \subseteq A \subseteq F$, where $F^{o}$ is the interior of $F$ in $X .[1]$

\section{Definition (1.1), [2]:}

A function $\mathrm{f}$ from a topological space $\mathrm{X}$ into a topological space $\mathrm{Y}$ is called $\mathrm{s}^{*}$-closed if and only if the image of every s-closed subset in $\mathrm{X}$ is closed in $\mathrm{Y}$.
It is clear that a set $\mathrm{A}$ of a topological space $X$ is said to be a semi-open (written sopen) if and only if there exists an open subset $\mathrm{U}$ of $\mathrm{X}$, such that $\mathrm{U} \subseteq \mathrm{A} \subseteq \overline{\mathrm{U}}$, where $\overline{\mathrm{U}}$ denotes the closure of $U$ in $X$. In any topological space $\mathrm{X}, \mathrm{SO}(\mathrm{X})$ denotes the collection of all s-open in X.[1].

\section{Proposition (1.2) [3]:}

Let $\mathrm{f}$ be a function from a topological space $\mathrm{X}$ into a topological space $\mathrm{Y}$ and $\mathrm{A} . \subseteq$ $X$. If $f$ is continuous, then $f(\bar{A}) \subseteq \overline{f(A)}$.

It is clear that if $X$ is a topological space and $A$ is a subset of $X$, then the intersection of all s-closed subsets of $\mathrm{X}$ each containing $\mathrm{A}$ is said to be the semi-closure of $\mathrm{A}$ (written as $\overline{\mathrm{A}}^{\mathrm{s}}$ ).[5]

\section{Proposition (1.3) [2]:}

Let $X$ be a topological space and let $A \subseteq$ $X$, then:

1. $\overline{\mathrm{A}}^{\mathrm{s}} \subseteq \overline{\mathrm{A}}$.

2. $\mathrm{A}$ is s-closed if and only if $\overline{\mathrm{A}}^{\mathrm{s}}=\mathrm{A}$.

3. $\overline{\mathrm{A}}^{\mathrm{s}}$ is the smallest s-closed subset containing A.

\section{Definition (1.4), [4]:}

A space $\mathrm{X}$ is said to be semi-compact space (written s-compact) if and only if for each s-open cover of $X$, there exist a finite sub cover of $\mathrm{X}$.

\section{Definition (1.5), [4]:}

Let $\mathrm{X}$ be a topological space and let $\mathrm{x}_{0} \in \mathrm{X}$. A set $\mathrm{G}$ in $\mathrm{X}$ is called a semi-neighborhood of $\mathrm{x}_{0}$ (written as s-neighborhood) if and only if $\mathrm{G}$ contains an s-open subset of $\mathrm{X}$ containing $\mathrm{x}_{0}$. The 
collection of all s-neighborhoods of $\mathrm{x}_{0}$, denoted by $\mathrm{N}_{\mathrm{x}_{0}}^{\mathrm{s}}$ is called the s-neighborhood system at $\mathrm{x}_{0}$.

\section{Definition (1.6), [5]:}

A subset $G$ of a topological space $X$ is sopen in $\mathrm{X}$ if and only if it is an s-neighborhood of each of its points.

\section{Definition (1.7), [5]:}

Let $\mathrm{X}$ and $\mathrm{Y}$ be topological spaces. A function $\mathrm{f}: \mathrm{X} \longrightarrow \mathrm{Y}$ is said to be irresolute function if and only if the inverse image of every s-open (s-closed) subset of $\mathrm{Y}$ is s-open (s-closed) in X.

\section{Proposition (1.8),[6]:}

Let $\mathrm{X}$ and $\mathrm{Y}$ be topological spaces and let $A$ be a subset of $\mathrm{Y}$. If $\mathrm{f}: \mathrm{X} \longrightarrow \mathrm{Y}$ is continuous and open function, then $f$ is irresolute.

\section{Proposition (1.9):}

Let $f$ be a function from a topological space $\mathrm{X}$ into a topological space $\mathrm{Y}$, then $\mathrm{f}$ is irresolute function if and only if for every $\mathrm{V} \in$ $\mathrm{SO}(\mathrm{Y}), \mathrm{f}(\mathrm{x}) \in \mathrm{V}$, there exist $\mathrm{U} \in \mathrm{SO}(\mathrm{X}), \mathrm{x} \in$ $\mathrm{U}, \mathrm{f}(\mathrm{U}) \subseteq \mathrm{V}$.

\section{Proof:}

Given $\mathrm{f}$ is irresolute. Let $\mathrm{x} \in \mathrm{X}$ and $\mathrm{V} \in$ $\mathrm{SO}(\mathrm{Y}), \mathrm{f}(\mathrm{x}) \in \mathrm{V}$

Since $f$ is an irresolute, then $f^{-1}(V) \in S O(X)$, since $f(x) \in V$, then $x \in f^{-1}(V)$, this implies that $\mathrm{f}^{-1}(\mathrm{~V})$ is an s-neighborhood of $\mathrm{x}$ by(1.6), .From (1.5) there exist $U \in \mathrm{SO}(X)$, such that $\mathrm{x}$ $\in \mathrm{U} \subseteq \mathrm{f}^{-1}(\mathrm{~V})$, then $\mathrm{f}(\mathrm{U}) \subseteq \mathrm{ff}^{-1}(\mathrm{~V}) \subseteq \mathrm{V}$.

Conversely, let $\mathrm{V} \in \mathrm{SO}(\mathrm{Y})$, to prove that $\mathrm{f}^{-1}(\mathrm{~V}) \in \mathrm{SO}(\mathrm{X})$.

For every $\mathrm{V} \in \mathrm{SO}(\mathrm{Y}), \mathrm{f}(\mathrm{x}) \in \mathrm{U}$, there exists $\mathrm{U} \in \mathrm{SO}(\mathrm{X}), \mathrm{x} \in \mathrm{U}$, such that $\mathrm{f}(\mathrm{U}) \subseteq \mathrm{V}$.

This implies that $\mathrm{U} \subseteq \mathrm{f}^{-1} \mathrm{f}(\mathrm{U}) \subseteq \mathrm{f}^{-1}(\mathrm{~V})$, then $\mathrm{x} \in \mathrm{U} \subseteq \mathrm{f}^{-1}(\mathrm{~V})$, this means that $\mathrm{f}^{-1}(\mathrm{~V})$ be an sneighborhood of $\mathrm{x}$ in $\mathrm{X}$.

Hence $f^{-1}(V) \in S O(X)$, then $f$ is irresolute.

\section{Definition (1.10), [3]:}

A filter $f$ on a set $X$ is a non-empty collection of non-empty subsets of $\mathrm{X}$, which has the following properties:

i. Every finite intersection of sets of $f$ belongs to $f$. ii. Every subset of $X$ which contains a set of $f$ belongs to $f$.

It is clear that if $\mathrm{f}$ is a function from a topological space $X$ in to a topological space $Y$ and $f$ is a filter on $X$ then $f(f)$ is a filter generated by the collection $\{f(F) / F \in F\}$.[3].

\section{Definition (1.11), [7]:}

A filter $f$ on a topological space $X$ is said to cluster at $\mathrm{x}_{0} \in \mathrm{X}$ (written $\mathrm{F} \propto \mathrm{x}_{0}$ ) if and only if for each $\mathrm{N} \in \mathrm{N}_{\mathrm{x}_{0}}$ and for each $\mathrm{F} \in \mathrm{F}, \mathrm{F} \cap$ $\mathrm{N}$ is non-empty.

\section{Definition (1.12), [6]:}

A filter $f$ on a topological space $X$ is said to s-cluster at $\mathrm{x}_{0} \in \mathrm{X}$ (written $\mathrm{F} \propto \mathrm{X}_{0}$ ) if and only if for each $\mathrm{N} \in \mathrm{N}_{\mathrm{x}_{0}}^{\mathrm{S}}$ and for each $\mathrm{F} \in \mathrm{F}, \mathrm{F} \cap \mathrm{N}$ is non-empty.

\section{Remark (1.13):}

Let $X$ be a topological space and $x_{0} \in X$. Let $F$ be s-cluster at $x_{0} \in X$, then $F$ is cluster at $\mathrm{x}_{0} \in \mathrm{X}$ (since every neighborhood of a point $\mathrm{x}_{0}$ of a topological space $\mathrm{X}$ is an s-neighborhood of $\mathrm{x}_{0}$ ).

But the converse is not true in general.

\section{Example (1.14):}

Let $X=\{1,2,3\}, \tau_{X}=\{\varnothing, X,\{1\}\}$

The collection of all s-open sets in $X$ is $\{\varnothing$, $\{1\},\{1,2\},\{1,3\}, X\}$

Let $f=\{X,\{3\},\{1,3\},\{2,3\}\}$, then $F$ is a filter on $X$.Also $f$ is cluster at 2 , since the only neighborhood of 2 is $X$ and for each $F \in F$, $\mathrm{F} \cap \mathrm{X} \neq \varnothing$. But $\mathrm{F}$ is not s-cluster at 2 since $\{1$, $2\}$ is an s-neighborhood of 2 and $\{3\} \in F,\{3\}$ $\cap\{1,2\}=\varnothing$.

\section{Remark(1.15):}

Let $\mathrm{X}$ be a topological space, then

(i) $\mathrm{X}$ is s-compact (compact) if and only if every filter on $\mathrm{X}$ has an s-cluster (cluster) point .[6] ([3]).

(ii) $\mathrm{f} \propto \mathrm{x}(f \propto \mathrm{x})$, if and only if $\mathrm{x} \in \cap\left\{\overline{\mathrm{F}}^{\mathrm{s}} \mid \mathrm{F}\right.$ $\in F\}(x \in \cap\{\bar{F} \mid F \in F\})$, where $f$ is a filter on $\mathrm{X}$ and $\mathrm{x} \in \mathrm{X}[6]([3])$.

(iii) Not that ,if $\mathrm{X}$ and $\mathrm{Y}$ are topological spaces, then $\mathrm{f}: \mathrm{X} \rightarrow \mathrm{Y}$ is continuous if and only if for each $\mathrm{X} \in \mathrm{X}$ and for each open subset $\mathrm{V}$ of $\mathrm{Y}, \mathrm{f}(\mathrm{x}) \in \mathrm{V}$ there exists an 
open subset $\mathrm{U}$ in $\mathrm{X}, \mathrm{x} \in \mathrm{U}$, such that $\mathrm{f}$ $(\mathrm{U}) \subseteq \mathrm{V} .[3]$.

\section{Proposition (1.16):}

If $\mathrm{f}$ is a continuous function from a topological space $\mathrm{X}$ into a topological space $\mathrm{Y}$ and $f \propto x$, then $f(f) \propto f(x)$, where $f$ is a filter on $X$ and $f(F)$ is a filter generated by $f$ in $Y$.

\section{Proof:}

Let $\mathrm{f}$ be a continuous function and let $f \propto x$, to prove $f(f) \propto f(x)$ is to prove for each $N \in$ $\mathrm{N}_{\mathrm{f}(\mathrm{x})}, \mathrm{N} \cap \mathrm{f}(\mathrm{F}) \neq \varnothing$, for each $\mathrm{F} \in \mathrm{f}$.

Let $\mathrm{V}$ be an open subset of $\mathrm{Y}$ such that $\mathrm{f}(\mathrm{x})$ $\in \mathrm{V}$, since $\mathrm{f}$ is continuous , then there exist $\mathrm{U}$ open in $\mathrm{X}$ such that $\mathrm{x} \in \mathrm{U}$ and $\mathrm{f}(\mathrm{U}) \subseteq \mathrm{V}$.(by (1.15)(iii)).

Since $x \in U$ and $U$ open subset of $X$ and $F \propto x$, then $U \cap F \neq \varnothing$, for each $F \in F$.

This implies that $\mathrm{f}(\mathrm{U} \cap \mathrm{F}) \neq \varnothing$, but $\mathrm{f}(\mathrm{U} \cap \mathrm{F})$ $\subseteq \mathrm{f}(\mathrm{U}) \cap \mathrm{f}(\mathrm{F})$, since $\mathrm{f}(\mathrm{U}) \subseteq \mathrm{V}$, then $\mathrm{f}(\mathrm{U}) \cap$ $\mathrm{f}(\mathrm{F}) \subseteq \mathrm{V} \cap \mathrm{f}(\mathrm{F})$, hence $\mathrm{V} \cap \mathrm{f}(\mathrm{F}) \neq \varnothing$

$\mathrm{V}$ be a neighborhood of $\mathrm{f}(\mathrm{x})$ in $\mathrm{Y}$, then $f(f) \propto f(x)$ in $Y$.

\section{Proposition (1.17):}

If $\mathrm{f}$ is an irresolute from a topological space $X$ into a topological space $Y$ and $f \stackrel{s}{\propto} x$, then $f(f) \stackrel{s}{\propto} f(x)$, where $f$ is a filter on $X$ and $f(f)$ is a filter generated by $\mathrm{f}$ in $\mathrm{Y}$.

\section{Proof:} (1.16).

The proof is similar to that of proposition

\section{S*-PROPER FUNCTIONS}

In this section we state and prove the main results of this paper.

First, we recall the following definition:

\section{Definition (2.1), [8]:}

A continuous function $\mathrm{f}$ from a topological space $X$ into a topological space $Y$ is said to be an $\mathrm{s}^{*}$-proper function if and only if $f \times \mathrm{I}_{Z}: X \times Z$ $\longrightarrow \mathrm{Y} \times \mathrm{Z}$ is $\mathrm{s}^{*}$-closed function for any topological space $Z$.

\section{Proposition (2.2):}

Let $\mathrm{f}$ be a continuous function from a topological space $\mathrm{X}$ into a topological space $\mathrm{Y}$, $\mathrm{A} \subseteq \mathrm{X}$, then $\mathrm{f}$ is an $\mathrm{s}^{*}$-closed function if and only if $f\left(\bar{A}^{s}\right)=\overline{f(A)}$

\section{Proof:}

Since $f$ is continuous, then $f(\bar{A}) \subseteq$ $\overline{\mathrm{f}(\mathrm{A})}$ (by (1.2)) and since $\overline{\mathrm{A}}^{\mathrm{s}} \subseteq \overline{\mathrm{A}}$ (by (1.3)), then $\mathrm{f}\left(\overline{\mathrm{A}}^{\mathrm{s}}\right) \subseteq \mathrm{f}(\overline{\mathrm{A}}) \subseteq \overline{\mathrm{f}(\mathrm{A})}$.

Since $f$ is $s^{*}$-closed and $\bar{A}^{s}$ is s-closed subset containing $A$, then $f\left(\bar{A}^{s}\right)$ is closed subset of $\mathrm{Y}$ containing $\mathrm{f}(\mathrm{A})$, therefore $\overline{\mathrm{f}(\mathrm{A})} \subseteq$ $\mathrm{f}\left(\overline{\mathrm{A}}^{\mathrm{S}}\right)$, and hence $\mathrm{f}\left(\overline{\mathrm{A}}^{\mathrm{s}}\right)=\overline{\mathrm{f}(\mathrm{A})}$.

Conversely, let $\mathrm{F}$ be s-closed subset in $\mathrm{X}$. To prove $f(F)$ is closed subset in $Y$.

Since $F$ is s-closed in $X$, then $F=\bar{F}^{s}$, and $f(F)$ $=\mathrm{f}\left(\overline{\mathrm{F}}^{\mathrm{s}}\right)=\overline{\mathrm{f}(\mathrm{F})}$

Therefore $f(F)$ is closed in $Y$, then $f$ is $s^{*}$ closed .

\section{Definition (2.3), [3]:}

A non-empty collection $B$ of non-empty subsets of a set $X$ is called a filter base for some filter on $\mathrm{X}$ if and only if for each $\mathrm{B}_{1}, \mathrm{~B}_{2}$ $\in B$, there exists $\mathrm{B}_{3} \in \mathrm{B}$, such that $\mathrm{B}_{3} \subseteq \mathrm{B}_{1} \cap$ $\mathrm{B}_{2}$

It is clear that the above definition is equivalent to:

A subcollection $B$ of a filter $F$ on a set $X$ is a filter base for $F$ on $X$ if and only if for each $F$ $\in F$, there exists $B \in B$, such that $B \subseteq F$, i.e., $F=\{F \subseteq X \mid B \subseteq F$, for some $B \in B\}$ is a filter on $\mathrm{X} .[3]$.

\section{Remark (2.4):}

(i) In [3], if $\mathrm{X}$ and $\mathrm{Y}$ be two topological spaces and $\mathrm{f}: \mathrm{X} \longrightarrow \mathrm{Y}$ be a continuous function, then $f$ is proper if and only if $f$ is a filter on $\mathrm{X}$ and $\mathrm{y} \in \mathrm{Y}$ is a cluster point of $f(f)$, then there is a cluster point xof $f$, $f(x)=y$

(ii) In [3], the constant function $\mathrm{f}: \mathrm{X} \longrightarrow \mathrm{P}$ is proper if and only if $\mathrm{X}$ is compact.

(iii) In [6], the constant function $\mathrm{f}: \mathrm{X} \longrightarrow \mathrm{P}$ is $\mathrm{s}^{*}$-proper if and only if $\mathrm{X}$ is s-compact.

\section{Proposition (2.5):}

Let $\mathrm{f}$ be a continuous function from a topological space $\mathrm{X}$ into a topological space $\mathrm{Y}$, then the following are equivalent:

1. $\mathrm{f}$ is $\mathrm{s}^{*}$-proper. 
2. $\mathrm{f}$ is $\mathrm{s}^{*}$-closed and $\mathrm{f}^{-1}(\mathrm{y})$ is s-compact for every $y$ in $Y$.

3. If $f$ be a filter on $X$ and if $y$ in $Y$ is a cluster point of $f(f)$, then there exists an s-cluster point $x$ of $f$, such that $f(x)=y$.

\section{Proof:}

$(1 \Rightarrow 2 \Rightarrow 1)$. See [8].

$(2 \Rightarrow 3)$. Suppose $F$ is a filter on $X$ and the filter generated by $f$ on $Y$ is $\{f(F) \mid F \in F\}$, $f(f) \propto y, y \in Y$

Since $\mathrm{f}$ is $\mathrm{s}^{*}$-closed and continuous, then $\mathrm{f}\left(\overline{\mathrm{F}}^{\mathrm{s}}\right)$ $=\overline{\mathrm{f}(\mathrm{F})}$, for every $\mathrm{F}$ in $\mathrm{f}$ (by (2.2)), by definition $y \cap \overline{(f(F))}_{y \in Y}$ be the set of cluster point of $f(F), y \in \overline{f(F)}=f\left(\bar{F}^{s}\right)$, then $f^{-1}(y) \cap$ $\overline{\mathrm{F}}^{\mathrm{s}} \neq \varnothing$, for every $\mathrm{F}$ in $\mathrm{F}$.

Let $B=\left\{f^{-1}(y) \cap \bar{F}^{s} \mid F \in f\right\}$ be a filter base on $\mathrm{f}^{-1}(\mathrm{y})$.

$\mathrm{By}(1.15)$ since $\mathrm{f}^{-1}(\mathrm{y})$ is s-compact, then there exist $\mathrm{x} \in \cap\left\{\mathrm{f}^{-1}(\mathrm{y}) \cap \overline{\mathrm{F}}^{\mathrm{s}} \mid \mathrm{F} \in \mathrm{f}\right\}$ and $\mathrm{x} \in$ $\cap\left\{\overline{\mathrm{F}}^{\mathrm{s}} \mid \mathrm{F} \in \mathrm{f}\right\}$, then $\mathrm{f}(\mathrm{x})=\mathrm{y}$ and $\mathrm{f} \propto \mathrm{s} \mathrm{x}$ $(3 \Rightarrow 2)$.

Let $\mathrm{A}$ be anon empty s-closed subset of $\mathrm{X}$ and let $F$ be the filter of subsets of $X$ which contains $\mathrm{A}$, then $\mathrm{A}$ is the set of s-cluster points of $f$.

Let $B$ be the set of cluster points of $f(f)$ on $Y$ $(f(f))$ is a filter generated by $f)$, then $B$ is a closed set in $\mathrm{Y}$ and $\mathrm{f}(\mathrm{A}) \subseteq \mathrm{B}$.

To prove $\mathrm{f}(\mathrm{A})=\mathrm{B}$, is to prove $\mathrm{B} \subseteq \mathrm{f}(\mathrm{A})$.

Let $\mathrm{y} \in \mathrm{B}$, then $\mathrm{f}(f) \propto \mathrm{y}$

(by (3)), there exists $x \in X$, such that $f \stackrel{s}{\propto x}$ and $f(x)=y$. But $A$ is the set of s-cluster points of $f$, then $x \in A$ and $y=f(x) \in f(A)$, this implies that $\mathrm{B} \subseteq \mathrm{f}(\mathrm{A})$.

By above $f(A)=B$, then $f$ is $s^{*}$-closed function.

Now, to prove for every $\mathrm{y} \in \mathrm{Y}, \mathrm{f}^{-1}(\mathrm{y})$ is scompact

Let $\mathrm{y} \in \mathrm{Y}$, either $\mathrm{f}^{-1}(\mathrm{y})=\varnothing$ or $\mathrm{f}^{-1}(\mathrm{y}) \neq \varnothing$,if $\mathrm{f}^{-1}(\mathrm{y})=\varnothing$, then $\mathrm{f}^{-1}(\mathrm{y})$ is s-compact . If $\mathrm{f}^{-1}(\mathrm{y}) \neq \varnothing$, then let $\mathrm{f}$ be a filter on $\mathrm{f}^{-1}(\mathrm{y}), \mathrm{f}(\mathrm{f})$ be a filter generated by $\mathrm{f}$ on $\{\mathrm{y}\}$, but $\{\mathrm{y}\}$ is compact and $\mathrm{y} \in\{\mathrm{y}\}$, then $\mathrm{f}(\mathrm{f}) \propto \mathrm{y}$ in $\{\mathrm{y}\} \subseteq \mathrm{Y}$ (by(1.15)).

This implies that $f(f) \propto y$ in $Y$.

(by (3)) there exists $x \in X$, such that $f \stackrel{s}{ } \propto x$, $\mathrm{f}(\mathrm{x})=\mathrm{y}$, then $\mathrm{x} \in \mathrm{f}^{-1}(\mathrm{y})$ and $\mathrm{f}^{-1}(\mathrm{y})$ is $\mathrm{s}$ compact.(by(1.15)

\section{Proposition (2.6):}

Let $\mathrm{f}$ be a function from a topological space $\mathrm{X}$ into a topological space $\mathrm{Y}$ and let $\mathrm{T}$ be open subset in $\mathrm{Y}$. If $\mathrm{f}$ is $\mathrm{s}^{*}$-proper, then $\mathrm{f}_{\mathrm{T}}$ : $\mathrm{f}^{-1}(\mathrm{~T}) \longrightarrow \mathrm{T}$ is $\mathrm{s}^{*}$-proper.

\section{Proof:}

To prove that $\mathrm{f}_{\mathrm{T}}$ is $\mathrm{s}^{*}$-proper, at first we must prove that $\mathrm{f}_{\mathrm{T}}$ is continuous function

Since $\mathrm{f}$ is $\mathrm{s}^{*}$-proper, then $\mathrm{f}$ is continuous, this implies that $\mathrm{f}_{\mathrm{T}}$ is continuous (see [3]).

Now, let $f$ be a filter on $\mathrm{f}^{-1}(\mathrm{~T}), \mathrm{y} \in \mathrm{T}$, such that $\mathrm{f}_{\mathrm{T}}(f) \propto \mathrm{y}$, then $\mathrm{f}(f) \propto y$ in $\mathrm{T}$

For every $N$ in $N_{y}$ in $T, N \cap f(F) \neq \varnothing$, for every $\mathrm{F}$ in $\mathrm{F}$, since $\mathrm{T}$ is open in $\mathrm{Y}$, then $\mathrm{N}$ is a neighborhood of y in $Y$ (see [3]).

Then $f(f) \propto y$ in $Y$, since $f$ is $s^{*}$-proper, then there exists $x \in X$, such that $\stackrel{s}{ } \propto x, f(x)=y$, then $x \in \mathrm{f}^{-1}(\mathrm{~T})$, hence $\mathrm{f}_{\mathrm{T}}$ is $\mathrm{s}^{*}$-proper (by (2.5)).

\section{Proposition (2.7):}

Let $f$ be a continuous function from a topological space $\mathrm{X}$ into a topological space $\mathrm{Y}$, and let $\left\{T_{i}\right\}_{i \in I}$ be an open cover of $Y$ such that $\mathrm{f}_{\mathrm{Ti}_{\mathrm{i}}}: \mathrm{f}^{-1}\left(\mathrm{~T}_{\mathrm{i}}\right) \longrightarrow \mathrm{T}_{\mathrm{i}}$ is an $\mathrm{s}^{*}$-proper, for every $\mathrm{i} \in \mathrm{I}$, then $\mathrm{f}: \mathrm{X} \longrightarrow \mathrm{Y}$ is an $\mathrm{s}^{*}$-proper.

\section{Proof:}

To prove that $\mathrm{f}$ is $\mathrm{s}^{*}$-proper

Let $F$ be a filter on $X$ and let $y \in Y$, such that $f(f) \propto y$, then for every $N$ in $N_{y}$ in $Y, N \cap f(F) \neq$ $\varnothing$, for every $F \in F$,

Since $\left\{T_{i}\right\}_{i \in I}$ is an open cover of $Y$, then there exists $i \in I$, such that $N$ is a neighborhood of $y$ in $T_{i}$, then $f(f) \propto y$ in $T_{i}$, this implies that $\mathrm{f}_{\mathrm{Ti}}(f) \propto \mathrm{y}$

But $\mathrm{f}_{\mathrm{T}_{\mathrm{i}}}$ is $\mathrm{s}^{*}$-proper, then there exist $\mathrm{x} \in \mathrm{f}^{-1}\left(\mathrm{~T}_{\mathrm{i}}\right)$, such that $f \stackrel{s}{ } \propto x, f(x)=y$

But $\mathrm{f}^{-1}\left(\mathrm{~T}_{\mathrm{i}}\right) \subseteq \mathrm{X}$, for every $\mathrm{i} \in \mathrm{I}$ and $\mathrm{x} \in \mathrm{X}$, hence $\mathrm{f}$ is $\mathrm{s}^{*}$-proper (by (2.5)). 
It is clear that every $\mathrm{s}^{*}$-proper is proper (by (1.13)), but the converse is not true in general.

For example, let $\mathrm{X}=[0,1]$, with the relative usual topological on $\mathrm{R}$, then the constant function $\mathrm{f}: \mathrm{X} \longrightarrow \mathrm{P}$ (when $\mathrm{P}$ is constant) is proper but it is not $\mathrm{s}^{*}$-proper, since $\mathrm{X}$ is compact but it is not s-compact.

\section{Proposition (2.8):}

Let $\mathrm{X}, \mathrm{Y}$ and $\mathrm{Z}$ be topological spaces and let $\mathrm{f}: \mathrm{X} \rightarrow \mathrm{Y}$ be an $\mathrm{s}^{*}$-proper function and $\mathrm{g}: \mathrm{Y} \longrightarrow \mathrm{Z}$ be a proper function, then $\mathrm{g}_{\mathrm{o}}$ $: \mathrm{X} \longrightarrow \mathrm{Z}$ is an $\mathrm{s}^{*}$-proper function.

\section{Proof:}

It is clear that the composition of two continuous functions is continuous, since $f$ is an $\mathrm{s}^{*}$-proper and $\mathrm{g}$ is a proper, then $\mathrm{f}$ and $\mathrm{g}$ are continuous functions and gof is acontinuous function.

Let $f$ be a filter on $X$ and $z \in Z$, such that $\left(g_{\circ} f\right)(f) \propto z$, then $g(f(f)) \propto z$,

Since $g$ is a proper, then there exist $y \in Y$, such that $\mathrm{f}(\mathrm{f}) \propto \mathrm{y}, \mathrm{g}(\mathrm{y})=\mathrm{z}$ (by (2.4)(i))

And since $f$ is an $s^{*}$-proper, then there exist $x \in X$, such that $\mathrm{F}^{\circ} \mathrm{s}, \mathrm{f}(\mathrm{x})=\mathrm{y}$

We know $\mathrm{g}(\mathrm{y})=\mathrm{z}$, then $\mathrm{g}(\mathrm{f}(\mathrm{x}))=\mathrm{z}$, that is mean that $\left(g_{\circ} f\right)(x)=z$, hence $g_{0} f$ is $s^{*}$-proper (by (2.5)).

\section{Proposition (2.9):}

Let $\mathrm{X}, \mathrm{Y}$ and $\mathrm{Z}$ be topological spaces, let $\mathrm{f}: \mathrm{X} \longrightarrow \mathrm{Y}$ be an onto irresolute function, let $\mathrm{g}: \mathrm{Y}-\mathrm{Z}$ be a continuous function. If gof $: X \longrightarrow Z$ is an $s^{*}$-proper, then $\mathrm{g}$ is an $\mathrm{s}$ *-proper.

\section{Proof:}

Let $f_{y}$ be a filter on $Y$ and $z \in Z$, such that $g\left(f_{y}\right) \propto z$, since $f$ is onto, then there exists $F_{x}$ in $X$, such that $f\left(f_{x}\right)=f_{y}$, this implies that $\mathrm{g}\left(\mathrm{f}\left(f_{\mathrm{x}}\right)\right) \propto \mathrm{z}$, this mean $(\mathrm{g}$ of $)\left(f_{\mathrm{x}}\right) \propto \mathrm{z}$

But $g_{\mathrm{o}}$ is $\mathrm{s}^{*}$-proper, then there exist $\mathrm{x} \in \mathrm{X}$, such that $f_{y} \propto x,\left(g_{\circ} f\right)(x)=z$, but $f$ is irresolute function, the $f\left(f_{x}\right) \stackrel{s}{\propto} f(x)$ (by (1.17)), then there exists $y \in Y$, such that $F_{\mathrm{y}} \propto \mathrm{s}, \mathrm{g}(\mathrm{y})=\mathrm{z}$, hence $\mathrm{g}$ is an $\mathrm{s}^{*}$-proper function (by (2.5)).

\section{Proposition (2.10):}

Let $\mathrm{X}, \mathrm{Y}$ and $\mathrm{Z}$ be topological spaces, let $\mathrm{f}: \mathrm{X} \rightarrow \mathrm{Y}$ be a continuous function and let $\mathrm{g}: \mathrm{Y} \longrightarrow \mathrm{Z}$ be one to one continuous function, such that $\mathrm{gof}_{\mathrm{o}}: \mathrm{X} \longrightarrow \mathrm{Z}$ be an $\mathrm{s}^{*_{-}}$ proper function, then $\mathrm{f}$ is an $\mathrm{s}^{*}$-proper.

\section{Proof:}

Let $f$ be a filter on $X$ and $y \in Y$, such $f(f) \propto y$.

Since $g$ is a continuous function (by (1.16)), $\mathrm{g}(\mathrm{f}(\mathrm{f})) \propto \mathrm{g}(\mathrm{y})$ in $\mathrm{Z}$, this mean $(\mathrm{gof})(f) \propto \mathrm{g}(\mathrm{y})$,

Since $g_{o}$ is an $s^{*}$ proper, then there exists $x \in$ $X$, such that $f \stackrel{s}{ } \propto x$ and $\left(g_{\circ} f\right)(x)=g(y)$, this mean that $\mathrm{g}(\mathrm{f}(\mathrm{x}))=\mathrm{g}(\mathrm{y})$,

Since $g$ is one to one, then $f(x)=y$.

Hence $\mathrm{f}$ is $\mathrm{s}^{*}$-proper function (by (2.5)).

\section{Proposition (2.11):}

Any $\mathrm{s}^{*}$-proper function $\mathrm{f}$ from $\mathrm{a}$ topological space $\mathrm{X}$ into a topological space $\mathrm{Y}$ is s-compact function.

\section{Proof:}

Let $\mathrm{K}$ be a compact subset of $\mathrm{Y}$, to prove $\mathrm{f}^{-1}(\mathrm{~K})$ is s-compact in $\mathrm{X}$.

Since $\mathrm{f}$ is an $\mathrm{s}^{*}$-proper, then $\mathrm{f}_{\mathrm{K}}: \mathrm{f}^{-1}(\mathrm{~K}) \longrightarrow \mathrm{K}$ is a $\mathrm{s}^{*}$-proper function (by (2.6)),

Since $\mathrm{K}$ is compact, then any constant function $\mathrm{g}: \mathrm{K} \longrightarrow \mathrm{P}$ is proper (by (2.4)(ii)).

By (2.8), $g_{o} f_{K}$ is $s^{*}$-proper, then $\mathrm{f}^{-1}(\mathrm{~K})$ is s-compact (by (2.4)(iii)).

Hence $\mathrm{f}$ is s-compact function.

\section{3-References}

[1] Leviene, N., "Semi Open and Semi Continuity in Topological Spaces", Amer.

Math. Monthly, 70 (1963), 36-41.

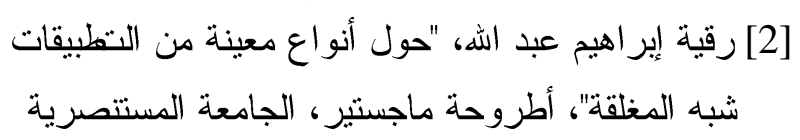

[3] Bourbaki, N., "Elements of Mathematics, General Topology", Chapter 1-4, SpringerVerlag, Berlin, Heidelberg, New York, London, Paris, Tpkyo, $2^{\text {nd }}$ Edition (1989).

[4] Bohn, E. and Lee Jon, G., "Semi Topological Groups", Amer. Math. Monthly, 72, (1965), 996-998.

[5] Navalagi, G. B., Definition Bank in General Topology, 54G (1991). 
[6] Laheeb Muhsen No'man, "On Some Types of Maps", M.Sc. Thesis, College of Science,Al-Mustansiriyah University,2005

[7] Willard, S., "General Topology", Addison Wesely, Inc., Mass (1970).

[8] حيدر جبر علي، "حول التطبيقات شبه المغلقة"،

أطروحة ماجستير، الجامعة المستنصرية (2001).

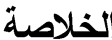

ان الهدف الرئيسي من هذا البحث هو دراسة نوع جديد

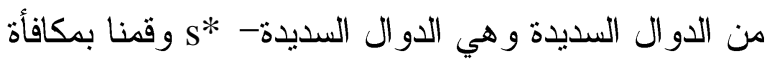

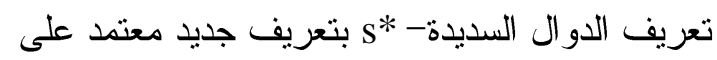

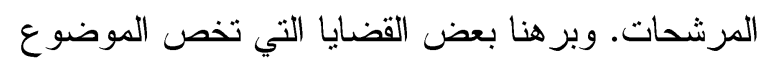

بأستخدام التعريف الاخير وحصلنا على بعض النتائج بشأن

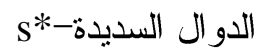

